\title{
UMA REFLEXÃO SOBRE AS CONTROVÉRSIAS TEÓRICAS E TERMINOLÓGICAS DOS FALSOS AMIGOS PORTUGUÊS/ESPANHOL
}

\section{ZAINE GUEDES DA COSTA}

RESUM 0: No presente trabalho tratamos de observar as controvérsias teóricas e denominações que envolvem o problema de confusão terminológica entre palavras que apresentam formas parecidas ou iguais, mas com sentidos diferentes, a saber, os falsos amigos português/espanhol. Nesse sentido, averiguamos que não existe unanimidade em relação à alcunha e à teoria que elas abarcam. Refletimos também que é preciso ir mais além da obviedade já constatada pela Linguística Histórica que palavras de línguas diferentes não podem ser configuradas como equivalentes ou correspondentes em sua estrutura. Dessa forma, finalizamos sugerindo, como alternativa plausível, uma abordagem interdisciplinar com o aporte da Psicologia Cognitiva, ou ainda o viés diacrônico, na tentativa de elucidar, pelo menos em parte, quais fatores teriam corroborado para a formação dos homônimos, parônimos e de palavras de mesmo étimo que desenvolveram através do tempo acepções particulares de sentido.

PALAVRAS-CHAVE: falsos amigos; português; espanhol; ensino-aprendizagem.

\section{INTRODUÇÃO}

Esta proposta investigativa originou-se a partir de observações (como professora de língua espanhola a estudantes brasileiros) em relação ao processo intuitivo do qual os aprendizes lançam mão durante a atividade de aquisição desse idioma. É parte do cotidiano dos docentes de espanhol como língua estrangeira, 
doravante LE, presenciarem alunos fazendo uso de elementos sintáticos, morfológicos, fonéticos, fonológicos e, sobretudo, lexiológicos do português durante o processo de internalização da língua meta. No entanto, o resultado dessa fusão manifesta efetivamente o mau uso e justificam as diferenças vistas como dificuldade de aprendizagem, as quais fundamentam a análise entre os dois sistemas linguísticos na perspectiva contrastiva (MIRANDA POZA, 2014; VITA, 2005).

No âmbito lexicológico - no qual se insere a proposta investigativa de nosso artigo - a integração desses elementos tem sido observada por diversas perspectivas, incidindo em diversas posições epistemológicas e, consequentemente, em algumas denominações que parecem refletir o campo investigativo que abarcam.

O termo falsos amigos, pelo fato de estar livre de contradições teóricas (BUGUEÑO MIRANDA, 2008), tem sido bastante utilizado pela maioria dos investigadores da área (MIRANDA POZA, 2014; MASIP, 2013; BUGUENO MIRANDA, 2008; VITA, 2005; CHUQUET e PARLLADIN 1987; VINAY e DARBALNET 1977; KOESSLER e DEROCQUINNY, 1928; entre outros). Já falsos cognatos é geralmente empregado por aqueles que relacionam o problema da confusão terminológica à raiz do elemento linguístico cognatum entre as duas línguas em contato (LEIVA, 1994; SABINO, 2006; entre outros). A terminologia heterossemânticos, por sua vez, possui um número bem menor de simpatizantes, pelo fato de diversos trabalhos investigativos indicarem que se trata de um termo tipicamente brasileiro (NASCENTES, 1934).

Por causa da não correspondência entre os conceitos e as denominações atribuídas, muitos são os entraves que permeiam as discussões sobre o tema, fato que se intensifica no caso de a língua nativa do aprendiz se assemelhar na forma à língua meta e, mais especificamente, se a coincidência for bem acusada no âmbito lexical, como é o caso do português e do espanhol. Nesse sentido, a acentuada proximidade desses dois sistemas induz a equívocos de índole semântica no processo de internalização textual, baseados no falso juízo que faz corresponder a proximidade formal e o sentido (FRANCIS, 2010).

Assim, mediante o quadro até aqui delineado, julgamos relevante discutir as perspectivas, denominações e objetivos diversos que versam sobre o tema à luz dos seguintes trabalhos investigativos, dentre outros: Koessler e Derocquiny (1928), Vinay e Darbalnet (1977), Chuquet e Parlladin (1987), Leiva (1994), Vita 
(2005), Sabino (2006), Bugueño Miranda (2008), Masip (2013) e Miranda Poza (2014).

\section{CONCEITOS E DENOMINAÇÕES}

Partindo da perspectiva histórica para a compreensão do termo mais utilizado pelos investigadores, é importante frisar que a tradição da denominação dada às pesquisas do termo faux amis, remonta às primeiras décadas do século XX. Sua aparição se deu pela primeira vez com a publicação da obra Les faux amis ou les trahisons du vocabulaire anglais em 1928 de autoria de Koessler e Derocquigny (1928). Nela, os investigadores compreendem o fenômeno considerando a etimologia dos léxicos enfrentados, a forma similar ou igual dos termos, e as acepções díspares que cada um deles aporta.

Para designar os falsos cognatos é bastante comum fazer referência àqueles pares de palavras que apresentam similaridade ou igualdade morfológica e/ou fonológica, mas que, no entanto, apresentam matizes particulares de sentido. Vita (2005) amparada no trabalho investigativo de Lado (1972), pondera que apesar do amplo uso da nomenclatura no meio acadêmico, não se encontra autoria para o termo por parte dos investigadores da área. No entanto, é bastante comum encontrar definições que atribuam ao léxico cognato o pressuposto de que são vocábulos que se originam de um outro.

Já para a nomenclatura heterosemántico, Vita (2005) chama atenção para o fato de que não existe evidência clara de sua origem, porém, acredita que sua primeira aparição se deu na Gramática para uso de brasileños de Antenor Nascentes (1934 apud Celada; González, 2000, p. 20). Nesse trabalho, é possível observar que o provável autor do termo, defina os heterosemánticos simplesmente como palavras similares com diferentes significados sem referir-se à origem ou ao étimo delas. Nesse sentido, Bugueño Miranda (2008, p. 2) adverte que o termo heterossemântico é inapropriado para dar conta de um evento claro e definido, já que tal termo acunhado por Nascentes, faz referência à pluralidade semântica lexical e não a um fenômeno linguístico específico.

Antes de darmos continuidade às reflexões teóricas e terminológicas, faz-se relevante mencionar que o problema dos desencontros semânticos que perpassam os falsos amigos - termo que preferimos adotar para nortear nossas discussões - incide na interface português/espanhol pelo fato de ambas línguas serem 
oriundas do latim e por compartilharem quase a totalidade do acervo lexical. Durão (2004) amparado na perspectiva contrastiva, considera que as línguas portuguesa e espanhola compartilham cerca de 90\% de igualdade léxica, sendo 60\% composto de cognatos correspondentes e 30\% de não correspondentes. Dentre outros fatores, isso se deve a uma análise comparativa e minuciosa feita por Richman (1965) que considera que dentre as línguas do tronco românico, português e espanhol são as que mais se assemelham tipologicamente. Esta constatação leva alguns investigadores, como Masip (2013), por exemplo, a defender o pressuposto de que tais línguas não são consideradas rigorosamente estrangeiras entre si:

Para sermos exatos, português e espanhol não são idiomas, estritamente falando, mas duas variantes dialectais do latim, que, por sua vez, pertence ao grupo latinofalisco, proveniente do tronco indo-europeu por meio do itálico. (Masip, 2013, p. 25)

Essa característica tipológica é, obviamente, um dos fatores responsáveis pelo problema de equívoco semântico-léxico de intercomunicação no momento do transpasso de uma língua a outra. De toda maneira, o que é indiscutível durante o processo comunicativo, é que a tão deduzida forma parecida ou semelhante, leva, frequentemente, à produção de erros, já que a extensão do significante induz ao significado da língua materna do aprendiz (DURÃO, 2004; MIRANDA POZA, 2014).

Nesse sentido, faz-se relevante destacar que o problema sobre o qual incidem os falsos amigos se insere na dualidade linguística deduzida por Saussure (2001[1916]) no tocante à relação estreita que existe entre a representação física (significante) e a representação da ideia (significado). A partir das perspectivas descritiva e contrastiva, observa-se que cada língua se constitui no percurso de sua história a partir de características e arranjos particulares. Para suprir as necessidades comunicativas de uma determinada comunidade linguística, os signos são selecionados de forma arbitrária por não possuir vínculo natural com a realidade à qual faz referência: “[...] o significante é imotivado, isto é, arbitrário em relação ao significado, com o qual não tem nenhum vínculo natural com a realidade" (SAUSSURE, 2001 [1916], p. 83). 
Cada língua faz um recorte de modo muito particular de sua realidade. O francês e o português, por exemplo, usam apenas uma palavra, mouton e carneiro respectivamente, tanto para o animal quanto para a carne pronta a ser servida. $\mathrm{O}$ inglês, no entanto, possui dois termos distintos: sheep designa o animal; mutton designa a porção de carne preparada (SAUSSURE, 2001 [1916]). Na língua espanhola, na palavra pollo, também encontramos o mesmo fenômeno que em francês, que tanto se refere à carne crua quanto à carne assada. Já em português, apesar de apresentar o vocábulo frango servir tanto para carne crua quanto para carne pronta, exibe também outra possibilidade para carne assada: galeto. Portanto, dentro dessa liberdade de escolha, as línguas que possuem termos oriundos de um mesmo tronco linguístico podem atribuir a eles sentidos diferentes.

Fazendo uma retrospectiva histórica concernente às investigações sobre o tema aqui proposto para análise, é possível perceber que anos após a primeira aparição do termo alcunhado pelos franceses, Vinay e Darbelnet (1977) fizeram uso da denominação falsos amigos para referir-se a pares de palavras que, apesar de pertencerem à mesma etimologia e apresentarem formas similares ou iguais, diferem em algumas de suas acepções.

Mais adiante, na década seguinte, encontramos em Chuquet e Parlladin (1987) uma proposta que parece ser precursora da dúvida em relação a um dos pilares conceituais defendido pelos franceses na década de 30: falsos amigos são palavras que possuem fonologia e/ou morfologia iguais ou semelhantes, mas que podem compartilhar ou não a mesma origem linguística.

No Brasil, nos anos 90, surge Leiva (1994) que demonstra, ainda nas primeiras páginas de sua dissertação de mestrado, seguir a linha de investigação histórica para análise do fenômeno; porém, no desenrolar das pesquisas, centrase em refletir sobre o processo angustiante de aprendizagem do falante de línguas próximas, especificamente, a portuguesa e a espanhola, propondo uma subdivisão bem interessante para o fenômeno em questão. Para a investigadora, o problema referido não só emerge de elementos lexicais, morfossintáticos e semânticos, mas também provêm do contexto cultural em que a palavra se insere. A hibridização desses elementos mais a percepção de mundo que cada falante adquire através de sua língua materna - é aqui que julgamos relevante a observação de Miranda Poza (2014) quando reclama a participação interdisciplinar da Psicologia Cognitiva no construto de uma nova linha de investigação sobre o tema 
- terminam sendo determinantes para o surgimento de um sistema intermediário, a saber, a interlíngua ${ }^{3}$.

Baseando-se em Robins (1971), Leiva faz uso do termo falso cognato para primeiro referir-se à formação de duas palavras latinas diferentes, mas que ao longo do percurso diacrônico, uma ou as duas línguas conservaram traços do elemento linguístico originário. E para tanto, trás, a modo de exemplo, os léxicos vaso /báso/ (espanhol) e vaso /vázu/ (português). No entanto, gostaríamos de advertir que o par de palavras dado carece de maiores explicações, já que vaso que se originou do latim vulgar vasum, que, por sua vez, veio do latim clássico vas/vasis, se ramificou tanto na língua portuguesa quanto na espanhola a partir de uma única raiz etimológica e não de raízes diferentes, como sugere a investigadora mais acima. Em consequência dessa origem, as línguas herdaram a ideia de 'recipiente' ou de 'receptáculo, da palavra 'mãe', sendo que esta particularizou o sentido para 'recipiente que serve para conter ou guardar líquido humano', enquanto aquela ampliou seu significado para 'recipiente que pode conter quaisquer tipos de líquidos ou sólidos' (COSTA, 2016; MIRANDA POZA, 2014; MASIP, 2013).

Para o segundo tipo, classifica-os como termos oriundos de uma única palavra, mas que conservam o significado original em ambas ou uma delas acrescenta um ou mais significados ou estreitam seu campo semântico ao longo do percurso histórico. Para tanto, usa como exemplo o par: /eSkizítu/ e /eGskisíto / que em português significa "esquisito" e em espanhol "estranho" ou "raro". Já para o terceiro tipo de falso cognato, categoriza como uma única palavra de origem com um ou mais significados, que são conservados por uma das línguas. A outra, no entanto, conserva apenas um ou nenhum dos significados, podendo até criar um termo para suprir a falta do(s) outro(s), como por exemplo, /suxestióN/ espanhol; /suzeStáuN/ português.

A última e quarta definição para o fenômeno não engloba palavras oriundas de mesma raiz linguística, e, portanto, não se refere aos falsos cognatos propriamente ditos, mas sim, a uma categoria de palavras que apenas correspondem ortograficamente e/ou fonologicamente, mas que apresenta raiz etimológica distinta com acepções particulares de sentido:

31 Termo técnico nascido a partir das investigações de Selinker (1972), para designar o processo anterior da aquisição do sistema linguístico não nativo. 
A definição de falsos cognatos, acima, não abrange um grupo que qualificamos de

Falsos Cognatos Acidentais, que Rose Nash (p. 159, 163) chama de "Accidental Cognates" na sua classificação de Cognatos do Englañol. Esse grupo de palavras não tem uma fonte comum, porém o consideramos falso cognato porque as palavras são iguais ou semelhantes em sua forma ortográfica e/ou fonológica, e podem causar o mesmo tipo de mal-entendido que o outro grupo de falsos cognatos, que podemos chamar de Propriamente Ditos. (LEIVA, 1994, pp. 16-17)

Para demonstrar essa categoria, a autora traz como exemplo de equivalência puramente ortográfica dos falsos cognatos acidentais, o par de palavras, /Ráto/ português e /ř́áto/ espanhol, por serem palavras não oriundas da mesma raiz etimológica.

No entanto, Leiva nos intima a observar que a não equivalência semântica deduzida aos falsos cognatos acidentais não se realiza em sua totalidade na amostragem inferida como modelo. Com base no Dicionário Priberam da Língua Portuguesa (DPLP), que apresenta uma versão contemporânea do português brasileiro, percebemos que a inferência semântica dada ao léxico rato (português), não ocorre somente a partir do entendimento de um pequeno mamífero roedor, mas também, em uma de suas acepções, a ideia de um curto espaço de tempo, de um momento ou de um instante. Ou seja, a ideia do rápido e do ligeiro, peculiar dos murídeos que também é advinda do latim, perpassa a língua portuguesa, mesmo que de modo secundário, e, portanto, termina não sendo um cognato tão acidental assim.

Outra investigadora que corrobora com importantes reflexões sobre esse tema é Vita (2005). Seu trabalho de mestrado intitulado La opacidad de la supuesta transparencia cuando los amigos funcionan como "falsos amigos", originou-se de observações feitas de alunos brasileiros que lançam mão do conhecimento imediato como ferramenta válida para aquisição da língua espanhola em sala de aula.

Ao longo de sua experiência docente, pôde considerar que, na esfera léxica, a confusão terminológica entre pares de palavras com formas similares e significados diferentes vai muito além da divergência semântica, forma como, frequentemente, o tema é tratado em materiais didáticos, anúncios e até mesmo em trabalhos de investigação científica. 
Assim como Miranda Poza (2014, p.8) observa em sua obra Propuesta de análisis de falsos amigos español y portugués: diacronía, campo léxico y cognición (semántica de los protótipos), Vita (2005) enfatiza, no início de seu trabalho, que o fenômeno dos falsos amigos é constatado, muitas vezes, como um evento de pouca relevância e percebido de maneira jocosa por diversos pesquisadores da área que deveriam contribuir, analisando o evento, além da obviedade do problema de interpretação que as palavras iguais ou parecidas, mas de sentido díspar, provocam.

Considerando o modelo contrastivo como relevante ao processo de ensinoaprendizagem de uma língua estrangeira, por causa da previsibilidade de erros, a investigadora pondera também que o modelo condutivista abriu espaço para a análise do processo abstrato de internalização de regras, tornando-se um importante aliado teórico a ser utilizado para responder, pelo menos em parte, os conflitos que o arquétipo anterior não conseguia satisfazer. Porém, apesar de relevantes, esses métodos desconsideram o aluno como sujeito do processo, sendo pertinente, então, uma proposta que considere o aprendiz socialmente inscrito e ativo durante a atividade de aquisição da língua meta.

Ao tratar de entender melhor os termos que, aparentemente, se referem ao mesmo fenômeno, a investigadora utiliza dicionários linguísticos. Em The Dictation of Historical and Comparative Linguistics (TRASK, 2000), a definição do termo 'cognato' é bastante similar ao que já fora percebido mais acima, já que se refere a palavras de diferentes línguas que tem origem em comum no mesmo idioma ancestral. Ao observar a explicação de Longman Dictionary of Languaje Teaching \& Applied Linguístics (RICHARDS Y PLATT, 1992), chama atenção que tanto o termo falsos amigos como o termo falsos cognatos possuem a mesma definição: palavras que apresentam formas semelhantes e significados distintos, sem alusão a origem ou ao étimo delas. Já para o termo heterossemântico, não foi encontrado nenhum registro nesses dicionários, ou seja, reforçando a hipótese de que tal alcunha tenha sido efetivada no Brasil.

Quando nos deparamos com as reflexões feitas, é quase impossível deixar de perceber a inquietação de Vita (2005) frente às acepções e nomenclaturas que permeiam o fenômeno. Para ela, as palavras não se definem puramente a partir de um aspecto formal ou de uma derivação linguística, antes, porém, as palavras são independentes de seu nome, já que são capazes de referir-se à uma atividade 
linguística que é simbólica e são capazes de criar conceitos, ordenar realidades, categorizar o mundo e materializar coisas que inexistem. Portanto, com como advoga Fiorin (2004), a vertente discursiva deve ser também incluída como aporte teórico para ampliar as discussões sobre a atividade de sentido que envolve o processo da produção linguística.

Dessa forma, a herança histórica não deve ser vista como fator exclusivo durante a construção de sentido de um léxico, é preciso que se considere também a influência contextual que perpassa a produção semântica através do tempo, quando se manifesta em um contexto, em que duas línguas se intercruzam e refletem diferentes acepções sócio-históricas. Nesse sentido, a modo de exemplo, o léxico /seRbíӨio/ 'serviço' que apresenta diversas acepções de uso no espanhol, sendo um deles /inodóro/ inodoro, ou seja, vaso sanitário. Porém, se um brasileiro escuta tal palavra, a interpreta como 'trabalho' ou 'labor' - se bem que, popularmente falando, no português brasileiro, a palabra /seRvísu/ também denota um fazer, de cunho estritamente particular durante um curto espaço de tempo no vaso sanitário, referindo-se às necessidades fisiológicas. Isso reforça, mais uma vez, a necessidade de uma pesquisa que parta da perspectiva diacrônica, que objetive desvendar, pelo menos em parte, as reais causas que levaram tais léxicos a acomodações particulares de sentido, sem perder, pelo menos em uma de suas acepções, o sentido advindo do étimo de origem. Assim, a materialização do que se concebe como similar ou parecido não deve ser entendida como um espaço livre de contradições e mal-entendidos, mas sim, percebido como uma zona onde a produção de sentido está sujeita a diversos fatores, inclusive, sociais e históricos.

Para esse propósito, é importante frisar que os problemas que envolvem o processo de tradução abundam no momento do transpasso de uma língua a outra, quando observados pelo viés da análise comparativa. Sobre isso, Miranda Poza (2014), menciona Mounin (1971) e Malmberg (1982) quando discorre sobre a apropriação de sentido que cada léxico aporta durante o exercício de representação de mundo que cada língua impõe ao falante nativo: "todo sistema lingüístico encierra un análisis del mundo exterior que le es propio, y que se diferencia de otras lenguas u otras etapas de la misma lengua” (MOUNIN, 1971, p. 94 apud 
MIRANDA POZA, 2014, p.16)32. Ou seja, quando se fala do mundo em línguas diferentes, obviamente, não se fala do mesmo mundo. Daí se origina a prerrogativa da impossibilidade de correspondência entre línguas, já que as formações linguísticas fazem conexões com outras formas de organização histórico-social e, portanto, não podem configurar-se como correspondentes. Por causa disso, é necessário que se considere a ciência que o indivíduo possui da não equivalência entre sistemas:

desde el primer contacto con una segunda lengua, el individuo se da cuenta de una cierta falta de correspondencia entre sus propias palabras y las de la lengua en cuestión. La traducción no es la mera sustitución de un término por otro. (MALMBERG, 1982, p. 24 apud MIRANDA POZA, 2014, p. 16)33

Assim, fica claro que o problema proposto para análise e discussão nesta linha investigativa tem sua gênese na confusão terminológica que induz o aprendiz a arrematar, de modo automático, a semelhança de forma com a igualdade de sentido.

Com tudo, Miranda Poza (2014) adverte que o fenômeno dos falsos amigos nem sempre é peculiar de línguas historicamente aparentadas, e que é preciso observar atentamente a tradução que é feita, porque qualquer descuido por parte do tradutor pode acarretar problemas graves de comunicação. E sobre isso Ceolin opina:

O problema da existência de falsos amigos é que estes podem numa tradução descontraída ou menos cuidadosa, comprometer o conteúdo semântico de um determinado enunciado e em consequência o ato comunicativo. (CEOLIN, 2003, p. 40)

Além da sensação desconfortante que pode causar uma tradução descomprometida, as investigações científicas atuais sempre fazem alusão ao fenômeno

32 Todo sistema linguístico inclui uma análise do mundo exterior que lhe é próprio, e que lhe diferencia de outras línguas ou outras etapas da mesma língua (tradução nossa).

33 Desde o primeiro contato com uma segunda língua, o indivíduo se dá conta de uma certa falta de correspondência entre suas próprias palavras e as da língua em questão. A tradução não pode ser considerada como uma mera substituição de um término por outro (tradução nossa). 
dos falsos amigos como um evento traiçoeiro que acomete o interlocutor durante a atividade de comunicação. Essa característica marcante é sempre abordada nos livros didáticos de língua espanhola como algo engraçado, que se configura como uma verdadeira armadilha tanto para leitores como para tradutores no momento de transpasso de uma língua a outra. No entanto, tal abordagem termina camuflando, em demasia, as mais diversas motivações de incompatibilidade de sentido por que passam homônimos, parônimos e léxicos oriundos de mesmo étimo (MASIP, 2013; MIRANDA POZA, 2014; MONTERO,1996 apud CEOLIN, 2003).

Outra investigadora que discursa sobre termos e teorias que ancoram o fenômeno dos falsos cognatos é Sabino (2006) através do trabalho investigativo Falsos cognatos, falsos amigos ou cognatos enganosos? Desfazendo a confusão teórica através da prática. Nele, enfatiza que na literatura linguística não existe um conceito a respeito dos falsos cognatos que esteja livre de contradições, já que a compreensão do que, de fato, compõe o fenômeno ainda é bastante confusa no âmbito acadêmico.

A grande maioria das teorias vigentes considera sinônimos os termos 'falsos amigos' e 'falsos cognatos', e, consequentemente, atribuem a eles a mesma fundamentação e características. A investigadora, apoiada em Ronai (1983), destaca que não existe uma definição teórica que seja unânime a esse propósito. Se por um lado há quem julgue a etimologia importante para identificação do falso cognato, existem outros que desconsideram sua origem no momento de classificá-lo. Se a análise parte da etimologia do vocábulo cognato, se pode verificar que a expressão que se originou no latim cognatu $(m)$, é nada mais que a junção daquilo que nasceu junto. Assim, as palavras que possuem diferentes origens, não podem ser consideradas cognatas. Nesse sentido, observa que os léxicos que, originariamente, nascidos juntos e que se assemelham na forma, mas que por evolução semântica passaram a aportar significações particulares, deveriam ser classificados como cognatos enganosos.

Por todas as reflexões feitas até agora, é importante ressaltar que Sabino não conceitua os falsos cognatos e falsos amigos como sinônimos um do outro. Se por um lado faz referência aos sentidos conotativos que um léxico 'amigo' pode apresentar, por outro, acredita que a expressão cognato, mesmo não apresentando sentido figurado, pode gerar sérios problemas semânticos. E por isso chama atenção para o fato de que muitas dessas unidades léxicas são cognatos 
verdadeiros, e batizá-los de falsos ou de dissimulados se mostra, no mínimo, controverso ou contraditório: "O que acontece, na verdade é que muitas dessas unidades lexicais são verdadeiros cognatos e atribuir-lhes o nome de falsos cognatos não parece ser sensato" (SABINO, 2006, p. 255). Assim, define cognatos enganosos como unidades léxicas de dois ou mais sistemas linguísticos distantes que provém do mesmo étimo, com ortografia e fonologia idêntica ou semelhante, porém acepções distintas, por causa da evolução semântica por que passaram ao longo do processo diacrônico. E para aquelas palavras que mantém um elo somente porque estão conectadas pela semelhança no plano da expressão, parece mais sensato caracterizá-los como os verdadeiros falsos cognatos.

Bugueño Miranda (2008), outro investigador brasileiro, parece estar ciente dos problemas terminológicos e teóricos que envolvem o fenômeno, e portanto, adota para suas reflexões a nomenclatura 'falsos amigos' por acreditar que tal termo esteja livre de contradições e de restrições epistemológicas, já que a denominação ‘falso cognato', por exemplo, tem como primazia a referência dos léxicos de mesma raiz etimológica, como o próprio termo sugere. Porém, apesar de referir-se ao sentido advindo da herança etimológica como uma das peças chaves para a definição do fenômeno aqui dissertado, considera que o desencontro de sentido que acomete os falsos amigos seja um evento praticamente exclusivo de um determinado momento das duas línguas, e que a perspectiva sincrônica é o que de fato interessa neste jogo de acepções semânticas durante o processo de ensino-aprendizagem da língua meta:

Os falsos amigos constituem sempre um problema quase exclusivamente entre estados sincrônicos de duas línguas. Só para fins filológicos considera-se, esporadicamente, problemas de falsos amigos desde uma perspectiva diacrônica (cf. por exemplo, BALDINGER 1974, 1981). A dimensão sincrônica está intimamente ligada ao fato de serem encontrados no processo de ensino-aprendizagem de uma língua estrangeira, embora isso aconteça também nas atividades tradutórias. (BUGUEÑO MIRANDA, 2008, p. 4)

Para o investigador, os falsos amigos se constituem a partir de três aspectos. O primeiro deles se concebe pelo fato de serem duas unidades de duas línguas que apresentam a mesma base etimológica, porém, uma dessas línguas perde uma significação e, portanto, se distancia semanticamente da outra unidade; o 
segundo tipo, se refere a duas unidades que se conectam através da mesma base etimológica, porém uma delas ganha uma nova significação. Para o terceiro e último tipo, o investigador chama a atenção para o fato de que são palavras que apresentam um choque homonímico por causa da convergência fonológica que existe entre elas. Pois bem, mesmo enfatizando que os entraves dos falsos amigos se manifestam, quando em contraste, entre estados coincidentes da língua, não deixa de ponderar a perspectiva diacrônica como um dos pilares do fenômeno.

Sobre a perspectiva histórica, encontramos diversos trabalhos investigativos (COSTA, 2016; MIRANDA POZA, 2014; ROBINS, 1971) que julgam oportuno para elucidar, pelo menos em parte, quais fatores contribuíram para que palavras cognatas com significantes iguais ou parecidos adquirissem matizes particulares de sentido em um dado momento da língua, visto que, a priori, o sentido denotativo do latim permanece nas derivadas línguas em uma ou mais acepções.

Sobre o evento homonímico, Bugueño Miranda (2008) ressalta que o fenômeno das palavras que apresentam a mesma estrutura fonológica, os mesmos fonemas, a mesma acentuação e ainda com significados completamente divergentes, se constitui como peça-chave para a caracterização dos falsos amigos. Porém, abre um parêntese quando menciona a grande dificuldade em diferenciar os falsos amigos e a polissemia deduzida aos heterossemânticos quando as palavras apresentam a mesma estrutura fonológica:

Ao se falar em palavras que têm a mesma estrutura fonológica, mas diferente significação, e atendendo à risca à significação de "homomorfos heterossemânticos", é difícil estabelecer uma diferença entre o fenômeno dos falsos amigos, a homonímia e/ou a polissemia. [...]. Se um falante do espanhol manifesta em português que uma iguaria é exquisita (na significação esp. “gostosa”), então a condição de igualdade fonológica entre port. esquisito e esp. exquisito o terá enganado efetivamente. (Bugueño Miranda, 2008, pp. 2-3)

Nesse caso, não podemos deixar de questionar, à luz das reflexões de Miranda Poza (2014), além do evento homonímico que discutiremos a seguir, em que consiste a igualdade fonológica deduzida pelo investigador, já que a transcrição do adjetivo em português - esquisito /eSkizítu/ em contraste com o adjetivo espanhol - exquisito /eGskisíto/ não são correspondentes em sua totalidade. $\mathrm{Na}$ 
língua portuguesa, a articulação do fonema oclusivo se realiza com a glote totalmente aberta, permitindo a passagem da corrente de ar, o que acarreta uma produção surda do som; enquanto que na língua espanhola, com a glote fechada, a corrente de ar instiga as pregas vocais a produzirem o fonema sonoro. Na sílaba tônica, também não se correspondem, pois o fonema fricativo /s/ quando situado entre vogais se manifesta sonoro em português, enquanto em espanhol, o fonema fricativo interdental se manifesta surdo.

Masip (2013, p. 20), outro importante investigador da área, não só atribui a identidade fonética e ortográfica aos falsos amigos, como também amplia seu ângulo discursivo e inclui o evento paronímico como característico do fenômeno. $\mathrm{E}$ sobre a homonímia define:

Identidade fonética e ortográfica de palavras de diverso sentido. Em português e espanhol, por exemplo, a palavra adobar soa e se escreve igual, mas, em português, significa fazer adobes com argila crua e, em espanhol, temperar comida, curtir peles. (MASIP, 2013, p. 20)

No entanto, ao estabelecer a homonímia34 como um dos pilares do fenômeno, nos convida a considerar os pressupostos deixados pela perspectiva histórica em relação de impossibilidade de equivalência de pronúncia e de escrita entre línguas diferentes, quando em situação de contraste, já que não podem ser consideradas idênticas, mas, sim, próximas. E sobre o que se entende por igual ou idêntico, julgamos pertinente inserir, logo a seguir, as observações de Miranda Poza (2014) sobre o exemplo deduzido por Masip (2013) para justificar a homonímia.

O léxico adobar carece de melhores explicações no quesito fonético, já que no item identidade ortográfica, a equivalência se realiza plenamente entre os dois sistemas linguísticos. Se a comparação for feita a partir da perspectiva fonológica, como sugerem Chuquet e Parlladin (1987) e Sabino (2006), a correspondência entre elas é perfeitamente coincidente: /adobáR/ espanhol, /adobáR/ portugués.

34 Homonímia. Identidade fonética e ortográfica de palavras de diverso sentido. Em português e espanhol, por exemplo, palavra adobar soa e se escreve igual, mas, em português, significa fazer adobes com argila crua e, em espanhol, temperar comida, curtir peles (MASIP, 2013, p. 20). 
No entanto, caso a análise seja feita a partir da comparação fonética de cada sistema, se constatará que elas não correspondem, estritamente falando. Adobar

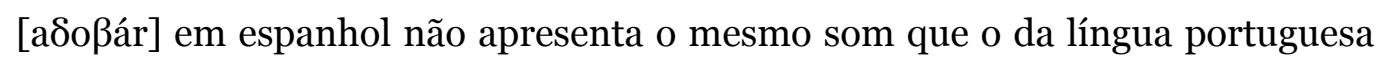
[adubár], pois além das inúmeras variações regionais em relação ao fonema vibrante múltiplo pós-vocálico [r], o ruído característico da passagem de ar referente aos fonemas $[\delta]$ e $[\beta]$ fricativos não se realiza na língua portuguesa, pois os fonemas [d] e [b] posicionados entre vogais só se articulam de modo oclusivo. O interessante é que o próprio Masip chega a reconhecer a homonímia, depois de categorizá-la, como fenômeno bastante complexo quando, em contraste, se opõe uma língua natural a uma outra, já que nem sempre as mesmas letras designam os mesmos sons.

Já para o evento paronímico, chega a categorizá-lo como palavras que apresentam semelhança, mas que diferem no som, na grafia, acepções e uso, e portanto, os mais frequentes entre os falsos amigos: crianza/ kriáNӨa/ espanhol, criança /kriáNsa/ português.

\section{CONSIDERAÇÕES FINAIS}

Diante do quadro até aqui exposto, consideramos que não existe unanimidade em relação à denominação e aos conceitos que as teorias abarcam. Se por um lado há quem considere a etimologia para identificação do fenômeno, por outro, existem aqueles que desconsideram a importância etimológica, e um terceiro grupo que inclui tanto os vocábulos de étimo comum quanto aqueles que não possuem a mesma origem. Nesse sentido, é importante ponderar que o evento dos falsos amigos português/espanhol não se esgota na obviedade da não equivalência de sentido entre formas similares. Antes, porém, é imprescindível que se considere outras formas de análise que respondam, pelo menos em parte, quais motivações semânticas estariam por trás desses desencontros e como cada língua particularizou o sentido de tais léxicos ao longo do tempo. Assim, acreditamos que diante de tantos desencontros, o aporte interdisciplinar da Psicologia Cognitiva que observa o processo de relação mental de percepção e de memória humana, sirva como umas das alternativas de pesquisa no campo epistemológico para elucidar o problema da confusão terminológica entre pares de palavras com formas parecidas ou iguais, mas de sentidos diferentes. Ou ainda, ponderar nas investigações, o viés diacrônico na tentativa de esclarecer quais fatores teriam 
corroborado para a formação dos homônimos, parônimos e das palavras de mesmo étimo que desenvolveram, através do tempo, acomodações particulares de sentido.

\section{REFERÊNCIAS}

BARALO OTTONELLO, Marta. Errores y Fosilización. Madrid: Universidad Antonio de Nebrija, 1996.

BENVENISTE, Émile. Natureza do signo linguístico. In: Problemas de linguística geral, Campinas: Pontes, 2005.

BUGUEÑO MIRANDA, Félix Valentín. Os dicionários de falsos amigos. Pelotas: Editora Universidade católica de Pelotas, 2008. p. 1-17.

CEOLIN, Roberto. 2003. Falsos amigos estruturais entre o português e o castelhano. In: Revista Philologica Românica. pp. 39-48. Disponível em: <www.romaniaminor.net/ianua/ianua04/ianua04_05.pdf>. Acesso em: 29 ago. 2015.

CHOMSKY, N. Reflexões sobre a linguagem. São Paulo: Cultrix, 1980.

CHUQUET, Hélène; PAILLARD, Michel. Approche linguistique des problèmes de traduction anglais-français. Paris: Orphys, 1987.

COROMINAS, Joan; PASCUAL, José Antonio. Diccionario Crítico Etimológico Castellano e Hispánico. Madrid: Gredos, 1983.

COSTA, Zaine Guedes. Falsos cognatos: revisão da fundamentação teórica e proposta de novas abordagens práticas para sua aplicação nos processos de ensino-aprendizagem de ELE no Brasil. 2016. Dissertação de mestrado em Linguística. Universidade Federal de Pernambuco. Recife. p. 125. 2016.

DICIONÁRIO PRIBERAM DA LÍNGUA PORTUGUESA [em linha] 2013, http://www.priberam.pt/dlpo/abatido [consultado em 23-11-2019].

DURÃO, Adja Balbino de Amorim Barbieri. Análisis de errores en la interlengua de brasileños aprendices de español y de españoles aprendices de portugués. $2^{\mathrm{a}}$ ed. mod. Londrina: Eduel, 2004.

HOUAISS, Antônio; VILLAR, Mauro de Salles. Dicionário eletrônico Houaiss da língua portuguesa. São Paulo: Objetiva, 2001.

KOESSLER, Maxime; DEROCQUIGNY, Jules. Les faux amis ou le pièges du vocabulaire anglais. Paris: Libraire Vuibert, 1928.

LADO, Robert. Linguística Contrastiva. Madrid: Ediciones Alcalá, 1973. 
LEIVA, Myrian. Jeanette Serey. Falsos cognatos em português e espanhol. Dissertação de mestrado em Linguística Aplicada. Universidade Estadual de Campinas, Campinas, 1994.

MASIP, Vicente. Armadilhas da língua espanhola: um guia completo. Recife: Editora Universitária da UFPE, 2013.

. Fonologia e Ortografia portuguesa. Um curso para alfabetizadores. São Paulo: E.P.U 2000.

MIRANDA POZA, José Alberto. Propuesta de análisis de falsos amigos en español y português: diacronia, campo léxico y cognición (semântica de los protótipos). Valladolid: Editorial Verdelís, 2014.

. La universidad ante los desafíos de la enseñanza de español en Brasil. Eutomia (Recife), v. 10, 2012, pp. 339-361.

. Introdução à Linguística. Recife: Editora Universitária da UFPE, 2011.

REAL ACADEMIA ESPAÑOLA. Diccionario de la lengua española. $22^{a}$ ed.2001. Disponível em: <http://www.rae.es/>. Acesso em: 15-11-2019.

ROBINS, Robert. General Linguistics: An Introductory Survey. Great Britain: Longman, 1971.

SABINO, Mariley Amadeo. Falsos cognatos, falsos amigos ou cognatos enganosos? Desfazendo a confusão teórica através da prática. ALFA Revista de Lingüística, São Paulo, 50 (2): 251-263, 2006.

SAUSSURE, Ferdinand de. Curso de Linguística Geral. 30. ed. São Paulo: Cultrix, 2001.

SELINKER, Larry. 1972. “Interlanguage”: International Review of Applied Linguistics In: Language Teaching 10(1-4): 209-232.

VITA, Claudia Pacheco. A opacidade da suposta transparência: quando "amigos" funcionam como “falsos amigos”. 193 f. Dissertação (Mestrado em Língua Espanhola e Literaturas Espanhola e Hispano-Americana) - Faculdade de Filosofia, Letras e Ciências Humanas, Universidade de São Paulo, São Paulo, 2005. 